\title{
Identidades em transição: Narrativas de mulheres negras sobre cabelos, técnicas de embranquecimento e racismo
}

\section{Identities in transition: Black women's narratives about hair, whitening techniques and racism}

\section{Indentidades en transición: Narrativas de mujeres negras sobre cabellos, técnicas de blanquiamiento y racismo}

\section{Aryanne Pereira de Oliveira e Oliveira*}

Universidade Federal do Rio de Janeiro - UFRJ, Rio de Janeiro, Rio de Janeiro, Brasil

\section{Amana Rocha Mattos**}

Universidade do Estado do Rio de Janeiro - UERJ, Rio de Janeiro, Rio de Janeiro, Brasil

\begin{abstract}
RESUMO
Neste trabalho, analisamos as narrativas de mulheres negras sobre seus cabelos, nos cuidados e apresentação dos mesmos, que trazem suas experiências e reflexões sobre como essas (trans)formaram suas identidades. As falas analisadas foram recolhidas de blogs e portais de notícias, disponíveis na Internet, em textos dedicados a discutir relações raciais, racismo, estética negra e feminismos negros. Para a análise, tomamos como referencial teórico os trabalhos de autoras/es que discutem questões raciais e processos de produção da identidade. $\mathrm{Na}$ análise do material foi possível pensar, a partir dos olhares dessas mulheres, seus processos de subjetivação desde a infância, na relação com as gerações mais velhas e o cuidado estético cotidiano. Em suas narrativas, dialogadas com referências teóricas que discutem processos de produção de identidade, bem como relações étnico-raciais, emergem experiências atravessadas por episódios explícitos e sutis de racismo. Os resultados apontam para a necessidade de uma maior interlocução da Psicologia com referenciais feministas e anti-racistas na teorização de processos de subjetivação de mulheres negras.
\end{abstract}

Palavras-chave: mulheres negras, práticas de cuidado, cabelos, racismo, psicologia social.

\begin{abstract}
In this work, we analyze the narratives of black women on their hair, selfcare practices and appearence, which bring their experiences and reflections on how these (trans)formed their identities. The speeches analyzed were collected from blogs and news portals, available on the Internet, in texts dedicated to discuss racial relations, racism, black aesthetics and black feminisms. For the analysis, we take as theoretical
\end{abstract}


referent the work of authors that discuss racial issues and processes of identity production. In the analysis of the material it was possible to think, from the perspective of these women, their processes of subjectivation since childhood, the relation with the older generations, and the daily aesthetic selfcare. In their narratives, dialogued with theoretical references that discuss processes of production of identity, as well as ethnic-racial relations, emerge experiences crossed by explicit and subtle episodes of racism. The results point to the need for a greater interlocution of Psychology with feminists and anti-racists references to theorize the processes of subjectivation of black women.

Keywords: black women, care practices, hair, racism, social psychology.

\section{RESUMEN}

En este trabajo, analizamos las narrativas de mujeres negras sobre sus cabellos, en los cuidados y presentación de los mismos, que traen sus experiencias y reflexiones sobre cómo estas (trans) formaron sus identidades. Las palabras analizadas fueron recogidas de blogs y portales de noticias, disponibles en Internet, en textos dedicados a discutir relaciones raciales, racismo, estética negra y feminismos negros. Para el análisis, tomamos como referencias teóricas los trabajos de autoras/es que discuten cuestiones raciales y procesos de producción de la identidad. En el análisis del material fue posible pensar, a partir de las miradas de esas mujeres, sus procesos de subjetivación desde la infancia, en la relación con las generaciones más viejas, y el cuidado estético cotidiano. En sus narrativas, dialogadas con referencias teóricas que discuten procesos de producción de identidad, así como relaciones étnico-raciales, emergen experiencias atravesadas por episodios explícitos y sutiles de racismo. Los resultados apuntan a la necesidad de una mayor interlocución de la Psicología con referencias feministas y antirracistas en la teorización de procesos de subjetivación de mujeres negras.

Palabras-clave: mujeres negras, prácticas de cuidado, el pelo, racismo, psicología social.

Cabelo. Já viu como, nesses programas de televisão que transformam a aparência da pessoa, as mulheres negras sempre têm o cabelo natural (crespo, enrolado, pixaim) na foto feia do "antes" e como, na foto bonita do "depois", alguém pegou um pedaço de metal quente e queimou o cabelo delas para ficar liso? [...] Quando você TEM cabelo natural de negro, as pessoas acham que você "fez" alguma coisa com ele. Na verdade, as pessoas com os afros e os dreads são as que não "fizeram" nada com o cabelo. (Chimamanda Adichie, Americanah)

O cabelo das mulheres negras materializa uma série de conflitos raciais vividos na sociedade brasileira. Considerando-se o padrão de beleza universal (e branco) compartilhado, podemos pensar as distintas experiências de consciência e/ou encobrimento desses 
conflitos na vivência de mulheres negras, articulando-as aos contextos históricos do país. A forma como mulheres negras cuidam de seus cabelos está profundamente articulada com seus processos de subjetivação e de produção de identidade. A formação das identidades de mulheres negras é atravessada pela maneira como seus cabelos são percebidos, colocando-as em diferentes lugares à medida em que modificam o cuidado e sua relação com os mesmos. Assim, pensar suas identidades exige levar em consideração um processo complexo, marcado por violências raciais, que atravessa o olhar para o próprio corpo e o olhar do outro para si mesmas. Na produção de suas identidades, cor da pele, traços e cabelos são elementos presentes na mediação com o outro, em uma sociedade marcada por relações patriarcais e racistas.

Nesse contexto, mulheres negras têm sido historicamente colocadas em situação de inferioridade econômica, política e social, e mulheres brancas são reiteradas como modelos positivos de identidade. A demarcação hierarquicamente inferior do lugar das mulheres negras, em uma sociedade de passado escravocrata, estabelece padrões de interação e submissão social. Mulheres negras crescem frequentemente ouvindo a máxima de que "apesar da cor, devem ser limpinhas, arrumadinhas, educadas...", tendo como ideal os estereótipos de beleza brancos. Em seus processos de socialização, meninas, garotas e mulheres negras aprendem a lidar com a tensão entre uma imagem construída a partir do processo de dominação racial e a luta por uma autoimagem positiva (Gomes, 2006; Schucman, 2018;). Práticas discursivas racistas, de maneira aberta ou velada, são acionadas constantemente por instituições, pela mídia hegemônica e pelo senso comum, como normas reguladoras que subalternizam seus corpos.

Neste trabalho ${ }^{1}$ analisamos as narrativas de mulheres negras sobre seus cabelos e suas reflexões sobre como cuidam e apresentam os mesmos, sobre suas experiências nesse processo e sobre como estas (trans)formaram suas identidades. As falas analisadas foram recolhidas de blogs e portais de notícias, disponíveis na Internet, em textos dedicados a discutir questões relacionadas a raça, racismo, estética negra e feminismos negros. Tomaremos como referencial teórico para nossa análise os trabalhos de autoras/es que discutem questões raciais e processos de produção da identidade.

\section{Entrelaçamentos de identidade, raça, gênero}

Definidos por muitos como "a moldura do rosto", os cabelos podem dar pistas sobre as origens, pertencimento a grupos sociais e hábitos de uma pessoa, aproximando ou afastando os sujeitos nessas relações. Possuem uma grande capacidade de expressão simbólica 
por estarem relacionados a um contexto sociocultural específico (King, 2015). Pensar os cabelos de mulheres negras implica refletir sobre a produção de identidades negras e sobre sua (trans)formação. As identidades não nascem conosco, não são inatas, mas sim produzidas socialmente. Elas dizem respeito a nossos modos de ser e estar no mundo. Os processos de formação de identidades são fluidos e contínuos, contextualizados histórica e culturalmente, e sua dimensão experiencial não pode ser desconsiderada. Nesses processos, os corpos (assim como os cabelos) não devem ser entendidos como fatores biológicos, mas como marcadores que são pensados a partir das ideologias culturais locais. Segundo Hall, na modernidade tardia as identidades não são unificadas, "elas não são nunca singulares, mas multiplamente construídas ao longo de discursos, práticas e posições que podem se cruzar ou ser antagônicos. As identidades estão sujeitas a uma historicização radical, estando constantemente em processo de mudança e transformação." (Hall, 2000, p. 108). Ou seja, as identidades são plurais uma vez que interiorizamos discursos, práticas e normas sociais, e transformam-se de acordo com nossas vivências.

É precisamente porque as identidades são construídas dentro - e não fora - da matriz discursiva, que nós precisamos compreendê-las como sendo produzidas em contextos históricos e institucionais específicos, por determinadas estratégias e processos. Além disso, elas emergem nas relações de poder e são, assim, mais o produto da marcação da diferença e da exclusão/inclusão do que o signo de uma unidade idêntica, naturalmente constituída, de uma "identidade" em seu significado tradicional - isto é, uma mesmidade que tudo inclui, uma identidade sem costuras, inteiriça, sem diferenciação interna (Brah, 2006; Hall, 2000).

Sendo a constituição da sociedade brasileira pautada pelo eurocentrismo, por valores e práticas racistas e que sustenta, ainda hoje, o mito da democracia racial ${ }^{2}$, corpos e cabelos negros remetem a posições subjugadas e marginalizadas. Nesse processo, os corpos das pessoas negras materializam uma série de estigmas sociais. Os processos de construção da identidade de pessoas negras não só se colocam em conflito com valores universais erigidos a partir do referencial branco dominante, como também se encontram fragmentados em nossa sociedade, pautada pelo ideário da brancura da pele e por valores e representações sociais hegemônicos brancos (Brandão, 2011).

$\mathrm{O}$ racismo e os estigmas raciais têm origem com o surgimento dos conceitos de raça e etnia. Diferentemente da comunidade científica do século XIX, que entendia raça como um fator biológico de raças humanas que estabelece a superioridade de uma sobre a outra, entendemos raça como sendo uma construção social política e cultural, produzida a partir de relações sociais e de poder (Schucman, 
2010). O racismo apresenta-se em atitudes e comportamentos sociais que pautam pertencimento e exclusão racial a partir de características corporais - cor da pele, tipo de cabelo, traços físicos e ideais de superioridade e inferioridade entre grupos.

De acordo com Borges, Medeiros e D`Adesky (2002), o racismo expressa-se de forma individual, através de atos discriminatórios entre indivíduos, e institucional, amparado pelo Estado, sendo observado em espaços escolares, midiáticos, corporativos, dentre outros. Nesse sentido, pensando em identidades que se produzem em, e a partir dos corpos, tanto o racismo expresso no nível individual quanto 0 racismo institucional atualizam 0 racismo estrutural que discrimina e hierarquiza raças, e contribuem nos processos de formação de identidade. Sobre a importância do corpo na construção da identidade, Louro afirma:

Nossos corpos constituem-se na referência que ancora, por fim, a identidade. [...] Os corpos são significados pela cultura e são, continuamente, por ela alterados. Talvez devêssemos nos perguntar, antes de tudo, como determinada característica passou a ser reconhecida (passou a ser significada) como uma "marca" definidora da identidade; perguntar, também, quais os significados que, nesse momento e nessa cultura, estão sendo atribuídos a tal marca ou a tal aparência de seu corpo. (Louro, 2001, p. 14).

As características de um determinado fenótipo são cultural e socialmente aceitas ou desqualificadas, e oferecem condições distintas para a produção de identidades. Os estereótipos associados às mulheres negras reiteram seus corpos como estando fora dos padrões (de beleza, de feminilidade, de humanidade), o que produz atravessamentos em suas identidades. As mulheres negras constituem suas identidades a partir das vivências que seus corpos lhes proporcionam. Esse processo é atravessado pelos ideais de gênero e raça valorizados socialmente, o que tem efeitos sobre suas vivências. Especificamente em relação ao conceito de raça, este é tomado aqui como uma "classificação social baseada numa atitude negativa frente a determinados grupos sociais, e informada por uma noção específica de natureza, como algo endoterminado. A realidade das raças limita-se, portanto, ao mundo social" (Guimarães, 1999, p. 9).

Segundo Carneiro (2005), a perspectiva relacional está presente no que se entende por racialidade, demarcando posições sociais a partir de uma construção social hierarquizante, que coloca a raça branca em posição privilegiada: "Disso decorre que ser branco e ser negro são consideradas polaridades que encerram, respectivamente, 
valores culturais, privilégios e prejuízos decorrentes do pertencimento a cada um dos polos das racialidades." (Carneiro, 2005, p. 34).

Não obstante as consequências da racialidade, ser mulher negra no Brasil implica ainda ser atravessada pelos valores e ideais que constituem o gênero. Se, ao ser proposto pelas feministas em meados do século $X X$, o conceito de gênero subverte e desnaturaliza a noção de sexo biológico (Dorlin, 2009), de lá para cá vemos que boa parte da discussão feminista tem se debruçado sobre as intersecções entre gênero e raça, em um movimento pautado por feministas negras e racializadas. Em produções distintas nesse campo, vemos reflexões sobre como a produção da opressão racial articula-se à subalternidade de gênero (Davis, 2016; Gonzales, 1984). As intersecções entre gênero e raça traçam "encruzilhadas", para utilizar o termo proposto por Kimberlé Crenshaw (1991), que materializam situações de vulnerabilidade física e psíquica para mulheres negras. Na medida em que construções de raça e gênero reificam desigualdades, observamos a manutenção de um senso comum que desumaniza mulheres negras em narrativas de objetificação, hipersexualização e/ou animalização, perpetuando percepções sociais que legitimam violações afetivas, físicas e psicológicas.

É nesse contexto que se coloca como tarefa pensar as mediações que perpassam o controle dos corpos negros. Neste trabalho, detivemos nossa reflexão nas narrativas que mulheres negras produziram sobre sua relação com seus cabelos - tarefa cotidiana, permeada pelo olhar de múltiplos outros. Como discutiremos na próxima sessão, a prática de mulheres e meninas negras de alisar ou submeter os fios a procedimentos estéticos invasivos e, muitas vezes, danosos à saúde, de maneira a se adequarem (ainda que inconscientemente) ao padrão de beleza branco, produz experiências marcantes, muitas vezes violentas, que não são experienciadas por mulheres brancas.

Para mulheres negras, alisamentos e tratamentos capilares que têm como referência ideais de beleza brancos operam, conscientemente ou não, afastamentos em relação aos seus antepassados negros/as. Os cabelos das mulheres negras na sociedade brasileira dizem respeito ao conflito social presente nas relações sociais. Ao ouvirem que seu cabelo é "ruim", as mulheres negras estão sendo também interpeladas em sua identidade. Por sua vez, a decisão por abandonar tratamentos capilares embranquecedores e assumir cuidados que incluem colorir, raspar, trançar e enfeitar os cabelos com adereços da cultura negra tem sido narrada por mulheres negras como processos acompanhados de experiências de autonomia e de ressignificação de suas identidades. A seguir, analisamos algumas falas de mulheres negras que publicizaram seus processos de transição capilar. 


\section{Vivenciando os cabelos: Narrativas em rede}

A utilização da Internet pelos movimentos feministas na última década tem propiciado experiências discursivas que partem de marcadores sociais distintos para pensar os processos de produção das identidades. As narrativas em primeira pessoa feitas por mulheres negras nas redes sociais têm se configurado como uma importante prática de enunciação de si e de visibilização de processos subjetivos historicamente apagados e silenciados (Braga, 2016; Malta \& Oliveira, 2016). Para mulheres negras, principalmente as mais jovens, as plataformas digitais têm funcionado como meio para compartilhamento de experiências, trajetórias e práticas de beleza cotidianas, com efeitos importantes no processo de ressignificação de suas identidades.

Se, em décadas anteriores, a mídia convencional invisibilizava os discursos das minorias, o advento da Internet com as redes sociais, os blogs e tantos outros espaços digitais possibilitou que as minorias se tornassem protagonistas de suas histórias. Nesse sentido, por meio desse novo modo de estar e se mostrar na sociedade, mulheres negras têm tornado públicos seus processos de auto reconhecimento enquanto mulheres e negras, e a ressignificação do que representam seus cabelos e as vivências por eles permeadas (Matos, 2015).

Neste trabalho, analisamos relatos de mulheres negras sobre seus cabelos, publicados em blogs e portais de notícias. Os relatos analisados foram localizados utilizando-se o site de busca Google, por meio das palavras-chave "cabelo", "identidade", "feminismo" e "negra". A busca foi feita para resultados do ano de 2015. Do material localizado, identificamos os relatos que foram publicados em blogs e portais de notícias, em textos que tematizassem a experiência de mulheres negras com seus cabelos. A partir daí, foram selecionados os relatos feitos em primeira pessoa, que trouxessem falas de mulheres negras que se submeteram e/ou foram submetidas a técnicas capilares como forma de embranquecimento, e que posteriormente abandonaram tais práticas. Todos os relatos selecionados encontram-se em sites de acesso público, disponíveis para consulta na Internet. Na Tabela 1 estão as informações sobre as autoras dos relatos $e$ as plataformas onde os mesmos foram disponibilizados. 
Tabela 1

Informações sobre os Materiais Consultados

\begin{tabular}{|c|c|c|}
\hline \multicolumn{3}{|c|}{ Página na Internet } \\
\hline $\begin{array}{l}\text { Rebeca Nascimento } \\
\text { (RS) } \\
\text { (Jornalista, idade não } \\
\text { informada) }\end{array}$ & Blogueiras Negras & $\begin{array}{l}\text { "Relato de uma } \\
\text { transição como } \\
\text { empoderamento e } \\
\text { reconhecimento" }\end{array}$ \\
\hline $\begin{array}{l}\text { Paloma Santos (PS) } \\
\text { (Professora de } \\
\text { Química, idade não } \\
\text { informada) }\end{array}$ & Projeto Redomas & $\begin{array}{l}\text { "Fala sobre o teu } \\
\text { cabelo, nêga!" }\end{array}$ \\
\hline $\begin{array}{l}\text { Priscila Flor (PF) } \\
\text { (Estudante de } \\
\text { Filosofia, } 19 \text { anos) }\end{array}$ & Geledés & $\begin{array}{c}\text { "Menina negra e a } \\
\text { escola" }\end{array}$ \\
\hline $\begin{array}{l}\text { Djamila Ribeiro (DR) } \\
\text { (Filósofa, idade não } \\
\text { informada) } \\
\text { MC Soffia (MCS) }\end{array}$ & Geledés & $\begin{array}{l}\text { "Mulher negra: o } \\
\text { outro do outro" }\end{array}$ \\
\hline $\begin{array}{l}\text { (Rapper, } 11 \text { anos) } \\
\text { Paula Lima (PL) }\end{array}$ & Terra & \\
\hline (Cantora e & & "Direito ao corpo: \\
\hline $\begin{array}{l}\text { Compositora, } 44 \\
\text { anos) }\end{array}$ & & $\begin{array}{l}\text { mulheres falam sobre } \\
\text { seus cabelos crespos" }\end{array}$ \\
\hline $\begin{array}{l}\text { Tassia Reis (TR) } \\
\text { (Cantora e } \\
\text { Compositora, } 25 \\
\text { anos) }\end{array}$ & & \\
\hline
\end{tabular}

Após a categorização dos relatos, os mesmos foram agrupados em três eixos de análise: (1) infância e socialização escolar; (2) intergeracionalidade; (3) cuidados capilares cotidianos. Essa divisão foi proposta para dialogar aspectos que aparecem como centrais nas falas com o referencial teórico pesquisado. Entendemos, entretanto, que essas dimensões se articulam nas vivências relatadas.

Durante a análise do material, chama atenção o fato de que, na maioria das vezes, o processo de embranquecimento das mulheres negras tem início ainda na infância. Nos relatos, podemos observar que experiências de sofrimento estão intimamente presentes na relação com os próprios cabelos:

"Tudo começou quando eu tinha cinco anos de idade. Cabelos crespos, nos ombros e um volume alto. Um cabelo que não tinha culpa de nada, mas que era chamado de ruim. Não havia muita representatividade ao meu redor. [...] Com sete anos decidi usar cabelo solto algumas vezes, mas logo desisti quando vi os comentários sobre o volume demais. Passei a acreditar que realmente era incômodo e feio ter o cabelo que nasci." (RN) 
A infância e a adolescência são períodos de grande importância nos processos de subjetivação. Se as experiências vividas a partir dos cabelos fenotipicamente herdados produzem sofrimento porque estes são associados a estereótipos negativos, o desejo de mudá-los (ou, mais especificamente, alisá-los) é relatado. Sendo a infância um período de produção de identidade e de subjetivação, "ele diz respeito à construção dessa criança enquanto sujeito em relação à própria imagem e também é resultado de relações sociais assimétricas, baseadas na imposição de modelos de homem, de mulher, de adultos, de raça e de etnia" (Gomes, 2006, p. 199). Logo, a falta de representatividade de imagens negras positivas também contribui para a forçosa escolha em se submeter a procedimentos que alterem a estrutura capilar, uma vez que os padrões estéticos acionam a dicotomia "bom e belo" versus "ruim e feio", estando os cabelos das mulheres negras no segundo polo. A submissão a tais procedimentos articula diretamente a estética à produção das identidades. Construir uma identidade negra positiva em uma sociedade que ensina desde muito cedo às pessoas negras que, para serem aceitas, é preciso negar-se a si mesmas é um desafio por essas pessoas (Gomes, 2005).

"E por que eu fiz tudo isso [com o cabelo]? Bom, na TV só havia mulheres de cabelo liso fazendo comercial de xampu. Sou da geração Xuxa e cansei de ver todas aquelas paquitas loiras e de olhos azuis. O que aquilo significava? Significava que meninas loiras podiam ser paquitas, que meninas de cabelo preto ou ruivo podiam tingir seus cabelos de loiro e serem paquitas e que eu, negra e de cabelo crespo, nunca poderia ser." (DR)

Podemos pensar que a adoção de procedimentos de tratamentos capilares configura-se como alternativa à vivência de situações abertamente racistas - ainda que não as impeçam de acontecer. Esse processo não se dá sem efeitos na construção subjetiva dessas mulheres.

Essas questões colocam-se de maneira intensa no espaço escolar, em que crianças e adolescentes convivem com conflitos e discriminações entre estudantes e também nas relações de ensino-aprendizagem, onde o imaginário social racista permeia os discursos legitimados de professores/as. A escola configura-se como um espaço disciplinador, com discurso normativo e homogêneo, produzindo marginalização e invisibilização dos corpos negros (Gomes, 2006, 2002).

"Na escola, cansei das vezes em que meu cabelo foi piada, considerado sujo, comparado a produtos de limpeza. Das 
inúmeras vezes em que os meninos não queriam fazer par comigo na festa junina, pois não dançariam com a 'neguinha'. $E$ o que mais doía é que toda a sociedade concordava com aqueles meninos." (DR)

"A escola nunca foi agradável comigo. Na oitava série eu e mais três alunos éramos os únicos negros em uma sala de quarenta e cinco alunos. Eu era a única que não tinha dinheiro para fazer tratamentos com químicas mais fortes. Ou seja, o cabelo delas descia. E o menino negro, raspava o cabelo. Ainda assim, nas brincadeiras de mau gosto TINHAM que evidenciar sua cor com a finalidade de humilhar. A cor negra servia como xingamento. $E$ os professores, incluindo negros, não falavam nada. Sempre tive essa sensação de que professores são surdos para determinadas questões. Porém, além de surdos, são mudos e cegos. Os meus foram. Sempre." (PF)

Sendo a subjetividade uma articulação de processos psíquicos, as experiências vivenciadas a partir dos cabelos a atravessam. Quando o espaço escolar, com suas práticas e normas, promove a homogeneização de identidades e subjetividades, produz também a marginalização dos diferentes a partir de mecanismos de exclusão e da reprodução do padrão dominante, fortalecendo a produção de subjetividades a partir destes padrões. De acordo com Bento (2012, p. 112),

"(...) a identidade é construída por meio do corpo e na convivência com o outro. Nosso "eu" é produto de muitos outros que o constituem. (...) Por meio do olhar, do toque, da voz, dos gestos desse outro, a criança vai tomando consciência de seu corpo, do valor atribuído a ele e ao corpo dos coetâneos, e construindo sua auto-imagem, seu autoconceito."

Em decorrência desse processo, o olhar do outro sobre o sujeito opera na produção da identidade, inclusive da identidade racial.

"Eu já alisei meu cabelo quando era pequena. A pressão da sociedade me fazia alisar, porque na escola as meninas ficavam falando que meu cabelo era duro, ruim, de bombril, essas coisas. Aí, pra não ser mais zoada por toda a escola, eu pedi pra alisar o cabelo, porque a gente sofre muito lá." (MS)

As experiências racistas vividas por meninas e garotas negras a partir de seus cabelos produzem sofrimento e podem marcar profundamente sua relação com o corpo. O/a professor/a e os adultos da escola, em geral, assumem lugar de referência para estudantes, e 
de importantes mediadores para os conflitos que ali ocorrem. Entretanto, como aparece nas falas acima, essa mediação não é sempre exercida quando crianças negras são alvo de racismo. Vale ainda destacar que o racismo não se manifesta apenas de forma incisiva e hostil, mas também, e, sobretudo, nos discursos cotidianos. Nesse sentido, as experiências vividas no contexto escolar deixam marcas que permanecem na vivência de mulheres negras. Por estarem associadas à dimensão corporal, é frequente que não sejam sequer nomeadas ou percebidas conscientemente por elas.

De acordo com Figueiredo (2008), a construção da subjetividade negra está intimamente associada às referências compartilhadas socialmente sobre o que é ser negro/a. Sendo estas referências tão importantes, sua existência ou ausência conduzirá a diferentes caminhos. Nesse sentido, o âmbito familiar se configura com um importante espaço de construção de sentidos e práticas de cuidado intergeracionais. Alguns dos relatos apontam que o hábito de tratar os cabelos quimicamente é uma prática exercida entre mulheres mais velhas e mais novas, quase como uma tradição familiar.

"As mulheres mais velhas que me cercavam já tinham o costume de passar ferros quentes nos cabelos nos fins de semana. Eu tinha muita vontade de fazer o mesmo. Quando completei dez anos já acreditava de verdade que era muito necessário colocar algo para relaxar os cachos ou alisar de uma vez por todas meus fios." (RN)

"É difícil dizer quando assisti a um alisamento pela primeira vez, mas sendo filha e sobrinha de mulheres que alisavam os próprios cabelos, já estava acostumada a participar dos demorados procedimentos, mesmo que em nossas cabecinhas de criança apenas as tranças fossem a solução. Foi só no início da adolescência que fui submetida ao meu primeiro tratamento químico, no quintal da casa de uma mulher negra também alisada, que dizia estar aplicando apenas um creme para "soltar meus cachos". Lembro desse dia e do quanto estávamos contentes, minha irmã e eu, de não ter mais que passar por doídas sessões de desembaraço. Como prometido, nossos cabelos estavam mesmo mais soltos e 'domados'." (PS)

Podemos dizer, a partir das falas acima e em diálogo com as autoras vistas até aqui, que a construção da subjetividade de mulheres negras em contextos racistas é marcada por experiências muito íntimas de rejeição do próprio corpo. Frequentemente, o desconhecimento de seu pertencimento racial inicia-se no círculo familiar, baseando-se em valores estéticos que não se enquadram em suas origens. Hooks (2005) ressalta que, para mulheres negras, fazer 
chapinha ou passar o ferro quente nos cabelos não significa explicita e necessariamente um "sacrifício", mas pode ser vivido como um ritual de transição entre o ser menina com penteados e trancinhas, e a maturidade, em que é possível se submeter a procedimentos e utilizar cabelos "soltos", significando "tornar-se" mulher. A autora fala do espaço de intimidade e acolhimento mobilizado nessas práticas entre mulheres negras de diferentes gerações, em que as meninas que utilizavam tranças para disfarçar os volumosos cabelos ouviam ensinamentos das mais velhas sobre como cuidar de seus cabelos. Com o surgimento de técnicas capilares mais sofisticadas e com promessas milagrosas, e com a mercantilização desses serviços em salões especializados, tal ritual doméstico passa a ser realizado por profissionais pagas, em uma relação em que o acolhimento e trocas entre mulheres negras foi sendo substituído pelo poder do capital.

Para as mulheres negras, é preciso aprender a "lidar" com os cabelos desde muito cedo. Como destaca Gomes, "a partir de uma perspectiva racial, a expressão "lida" incorpora a ideia de trabalho forçado e coisificação do trabalho do escravo e da escrava. Lembra, também, as estratégias do regime escravista na tentativa de anular a cultura do povo negro" (Gomes, 2008, p. 7). Nesse sentido, mesmo passados tantos anos desde a abolição da escravatura, tal prática atravessada por experiências de sofrimento ainda se perpetua na regulação de corpos, por meio dos ideais embranquecedores de beleza. Os cabelos de garotas e mulheres negras são associados a um imaginário social de marginalização. Quando a mulher negra precisa lidar com seu cabelo de modo a sentir-se incluída neste referencial, vê-se despendendo energia e recursos para se encaixar no padrão estético branco. Em contrapartida, no momento em que decide romper com este padrão, podemos dizer que se produzem novos sentidos para o verbo "lidar", mobilizando-a para se contrapor a esses ideais e sustentar uma posição estética e política na sociedade, em uma prática de autocuidado. Em ambas as situações, seja ao lidar com o cabelo para se adequar aos padrões, seja ao estabelecer uma nova lida para romper com estes padrões, estamos falando de um trabalho que é feito consigo mesma, na dimensão corporal.

"A mãe passava muito creme no cabelo das crianças, e alisava porque conseguia fazer um corte. Acho que tinha uma facilidade para a própria mãe lidar com o cabelo. Não era comum ver cabelo natural." (PL)

"Depois de um tempo, ela começou a fazer um relaxamento que libera os cachos, vamos dizer assim, que era mais "fácil" de pentear." (TR) 
A crescente oferta de salões e produtos voltados para mulheres negras consolida um mercado cada vez mais lucrativo. Se estas antes não eram consideradas pelo segmento da indústria cosmética como um consistente público consumidor, atualmente esse mercado tem sido identificado e reconhecido, com oferta cada vez maior de produtos voltados para mulheres negras. Falando especificamente de produtos para o cabelo, vale ressaltar que nem todo procedimento cumpre o que promete, produzindo também experiências de dor, como podemos observar no relato abaixo:

"Lembro de uma vez que saí na rua, inclusive minha mãe tinha até feito um desses relaxamentos, mas o cabelo continuava bem volumoso, e aí saí na rua me sentindo maravilhosa, e em dois minutos começaram a me zoar e eu voltei pra casa e prendi o cabelo. Eu só queria ser aceita." (TR)

Precisamos, ainda, nos atentar ainda para o fato de que a valorização mercadológica do cabelo crespo pode reforçar o discurso de uma imagem estereotipada sobre mulheres negras, tendo como objetivo a obtenção de lucro a partir de discursos que reificam a alteridade a partir da exotização da estética negra.

Nos relatos também esteve presente a experiência de suportar, de maneira consciente, o sofrimento ao se submeter aos procedimentos de tratamento dos cabelos. Ou seja, ainda que essas mulheres soubessem que determinada prática dói, dá trabalho, e pode até ser danosa à saúde por ser um procedimento químico, não interrompiam necessariamente seu uso.

"Minha vingança era encharcar meu cabelo-maldição com químicas que eu nem fazia ideia como eram compostas. E a cada aplicação, aquela queimação no couro cabeludo, aquela agonia, dor, pescoço dolorido por causa daquela infeliz cadeira do salão. Bem, quando eu ia ao salão!" (PF)

"Aguentava como verdadeira heroína os minutos de ardência e as sequências de enxágue, neutralização, escova e chapinha. Meu couro cabeludo era sensibilizado durante horas, queimado quimicamente e pelo secador e chapinha. Eram horas respirando um vapor sufocante e umedecendo os olhos que ardiam, tomando água pra controlar a secura da boca. Eu, profissional e professora de química, me submetia a isso a cada três meses. Sim, porque não durava. Saía do salão com cabelos lisos (não havia mais cachos), brilhantes e elogiáveis, que na semana seguinte não estavam mais assim." (PS) 
Considerando-se esta última fala, e pensando os riscos e dores ocasionados pelos procedimentos estéticos, é necessário pensarmos os efeitos que esse processo produz nas subjetividades dessas mulheres, tais como sentimentos de inadequação, baixa autoestima, e mesmo auto-ódio. Suas falas nos dão pistas de que o sofrimento e os danos causados pelos procedimentos são suportados como maneira de escapar do racismo de que são alvo, mas também indicam processos autodestrutivos, em que uma parte de seus corpos é tomada como inimiga: "Minha vingança era encharcar meu cabelomaldição". Dessa forma, podemos deduzir que a dor do racismo se sobrepõe à dor dos procedimentos estéticos, tornando estes últimos releváveis frente ao sofrimento maior que a discriminação racial pode provocar. Vale ainda ressaltar que essa prática que exige esforço e, de certa maneira, alguma anulação de si - nomeada, com ironia, como "heroísmo" por PS ("Aguentava como verdadeira heroína"), não garante que essas mulheres deixem de passar por situações racistas. De acordo com King, "O número de técnicas de alisamento e o vínculo deste procedimento com diversas problemáticas sociais reforça sua importância, dadas suas recorrência e atualidade. Ele reforça a negação de cabelos crespos dentro desta sociedade, que tem em sua origem o profundo histórico do racismo." (King, 2015, p. $6)$.

Para além da negação dos cabelos, derivada de uma leitura social que associa cabelos crespos a uma imagem negativa, vale destacar a falta de representatividade de mulheres negras em diferentes contextos, nos quais as mulheres brancas de cabelos lisos frequentemente ocupam lugares positivos ou desejáveis. A mídia hegemônica é responsável por repercutir diariamente imagens de feminilidade que excluem mulheres negras. Juntos, racismo e sexismo se impõem diariamente à sociedade - e às mulheres negras - pelos meios de comunicação. A publicidade, os lugares de destaque na dramaturgia, os estereótipos de beleza reiterados cotidianamente sinalizam às mulheres negras que, para serem desejadas, aceitas e valorizadas, é preciso mudar (embranquecer) - especialmente os cabelos. Essas mensagens têm efeitos devastadores sobre a construção de uma individualidade e uma identidade positivas em meninas, garotas e mulheres negras (Hooks, 2005).

Se o processo de formação de identidades é oriundo de relações contextualizadas, localizadas, as narrativas midiáticas fazem parte desse processo, pautando modos de ser, viver e aparecer. Os movimentos de ressignificação das identidades, entretanto, também têm sido permeados por tais relações. Se a mídia hegemônica e branca tem compactuado e reproduzido sistematicamente o racismo estrutural, as redes sociais surgem como um importante dispositivo para o tensionamento dessas narrativas (Malta \& Oliveira, 2016; Matos, 2015; Mattos \& Silva, 2014). 
Nesse sentido, as experiências de (re)descoberta de si, no reencontro de mulheres negras com seus cabelos crespos e cacheados, e os processos de transição capilar (em que se abandonam os procedimentos de alisamento dos fios), trazem vivências de empoderamento e representatividade para essas mulheres.

"O auto boicote aconteceu várias vezes durante meses. [...] Acontece que eu não tinha mais dez anos de idade, havia representatividade ao meu redor e já estava devidamente convencida de que era bonita sem o falso cabelo liso. Eu era bonita sem me agredir. Em março do mesmo ano tinha raiz crespa para esticar, eu nunca mais voltaria a fazer isso. Decidi entrar em transição capilar. A força nasceu a partir do momento que reconheci minha identidade. Precisei da transição para me reconhecer uma mulher negra. Para conhecer minha ancestralidade, para saber de onde vim e para respeitar o que sou. [...] O que aconteceu dentro da minha cabeça em um ano e meio transcende toda a transição capilar que findou em novembro desse ano. Reconheço-me uma mulher negra, que foi vitimada pelo racismo desde muito pequena, mas que só após muito tempo pôde perceber suas raízes, sua cor, sua ancestralidade. Sei que tenho pleno direito de usar meu cabelo como bem quiser, mas sei que isso nunca mais passará por desejo de ser aceita numa sociedade mediocramente fundamentada na opressão racista e em seus meios de embranquecimento fortes e sutis." (RN)

Vemos aqui a importância da representatividade e do acesso à narrativas e referenciais de ancestralidade para que outras práticas e escolhas sejam possíveis. Fato é que o acesso à informação acerca de história, e a importante representatividade positiva de imagens diversas de negritude podem modificar a maneira como mulheres negras vivem as experiências a partir de seus cabelos.

\section{Considerações Finais}

Neste trabalho, partimos da concepção de que as identidades estão em constante processo de transformação, atravessadas por questões de gênero e raça, para pensar os processos de subjetivação de mulheres negras em contextos racistas. Os cabelos constituem parte importante desse processo e, articulando identidade, raça e gênero, nos possibilitam aproximar-nos de suas experiências, bem como constituem importantes disparadores para que mulheres negras produzam narrativas sobre seus processos de subjetivação. 
Considerando-se que mulheres negras estão inseridas em uma sociedade racista, que nega e oprime suas existências, sua beleza e identidades, falar sobre cabelos significa avançar na luta antirracista e feminista. Tendo em vista as múltiplas questões que perpassam esta discussão e as inúmeras experiências e traumas que o permanente trato com seus cabelos proporciona, e na medida em que novas técnicas e penteados se pluralizam, entendemos que novas situações se configuram, nas quais identidades e subjetividades estão a todo tempo sendo confrontadas e redesenhadas.

A análise de falas de mulheres negras sobre seus cabelos aqui proposta nos levou a pensar, a partir de seus olhares, os processos de subjetivação desde a infância, a relação com gerações mais velhas, e o cuidado estético cotidiano. Em suas narrativas, dialogadas com autoras/es que pensam as identidades, o gênero e a raça em perspectivas feministas e antirracistas, percebemos o quanto as experiências de mulheres negras são profundamente marcadas por violências explícitas e sutis de racismo. Este trabalho oferece um recorte analítico que, em função do material analisado (relatos produzidos previamente à realização desta pesquisa), possui limitações. A análise dos efeitos subjetivos e identitários dos cuidados capilares se restringiu a esses enunciados, não tendo sido feitas outras perguntas a essas mulheres a partir de suas falas, por conta do desenho metodológico. Além disso, as mulheres autoras dos relatos vivem em contextos urbanos e com acesso às tecnologias e à mídia. Seria interessante, em trabalhos futuros, investigar esses processos em outros contextos sociais. Partindo do que foi discutido neste artigo, entendemos que a Psicologia Social precisa aprofundar seus estudos em duas importantes direções: compreender os efeitos psicológicos da vivência do racismo em pessoas negras; e pensar a produção da branquitude como padrão moral, estético e ético, em suas intersecções de gênero e raça.

\section{Referências}

Bento, M. A. (2012). A identidade racial em crianças pequenas. In M. A. Bento (Org.), Educação infantil, igualdade racial e diversidade: aspectos políticos, jurídicos, conceituais ( $\mathrm{pp} 98-$ 117). São Paulo: Centro de Estudos das Relações de Trabalho e Desigualdades - CEERT.

Borges, E., Medeiros, C. A., \& D'Adesky, J. (2002). Racismo, preconceito e intolerância. São Paulo: Atual.

Braga, L. A. (2016). Blogueiras negras em destaque na Revista Raça Brasil: Promovendo o orgulho através da estética. Temática, 12(5), 195-209. Recuperado de 
http://www.periodicos.ufpb.br/index.php/tematica/article/view/ 28924/15375

Brah, A. (2006). Diferença, diversidade, diferenciação. Cadernos Pagu, (26), 329-376. Recuperado de 10.1590/S010483332006000100014.

Brandão, M. O. B. (2011). Representações sócio-discursivas e identitárias no Espaço Escolar: Etnias no con(texto) (Dissertação de mestrado). Universidade Federal da Grande Dourados, Dourados, MS, Brasil.

Carneiro, S. (2005). A construção do outro como não-ser como fundamento do ser (Tese de Doutorado). Universidade de São Paulo, São Paulo, SP, Brasil.

Costa, E. V. (1979). Da Monarquia à República: Momentos Decisivos. São Paulo: Ciências Humanas.

Crenshaw, K. W. (1991). Mapping the Margins: Intersectionality, Identity Politics, and Violence Agains Women of Color. Standford Law Review, 43(6), 1241-1299. doi: $10.2307 / 1229039$

Davis, A. (2016). Mulheres, raça e classe. São Paulo: Boitempo.

Dorlin, E. (2009). Sexo, género y sexualidades: Introducón a la teoría feminista. Buenos Aires: Nueva Visión.

Figueiredo, A. (2008). Gênero: Dialogando com os estudos de gênero e raça no Brasil. In O. Pinto \& L. Sansone (Org.), Raças Novas Perspectivas Antropológicas (237-255). Salvador: ABA EDUFBA.

Gomes, N. L. (2008). Sem perder a raiz: corpo e cabelo como símbolos da identidade negra. Belo Horizonte: Autêntica.

Gomes, N. L. (2006). Educação, raça e gênero: Relações Imersas na Alteridade. Cadernos Pagu, (6/7), 67-82. Recuperado de https://periodicos.sbu.unicamp.br/ojs/index.php/cadpagu/articl e/view/1862/1983

Gomes, N. L. (2005). Alguns termos e conceitos presentes no debate sobre relações raciais no Brasil: Uma breve discussão. In Educação Anti-racista: Caminhos abertos pela Lei federal $n^{\circ}$ 10.639/03 (pp. 39-62). Brasília: MEC, Secretaria de educação continuada e alfabetização e diversidade.

Gomes, N. L. (2002). Trajetórias escolares, corpo negro e cabelo crespo: reprodução de estereótipos ou ressignificação cultural? Revista Brasileira de Educação, (21), 40-51. Recuperado de $10.1590 /$ S1413-24782002000300004.

Gonzales, L. (1984). Racismo e sexismo na cultura brasileira. Revista Ciências Sociais Hoje, Anpocs, (2), 223-244. Recuperado de https://edisciplinas.usp.br/pluginfile.php/247561/mod_resource /content/1/RACISMO\%20E\%20SEXISMO\%20NA\%20CULTURA $\% 20 B R A S I L E I R A . p d f$

Guimarães, A. S. A. (1999). Racismo e Anti-racismo no Brasil. São Paulo: Editora 34. 
Hall, S. (2000). Quem precisa da identidade? In T. T. Silva (Org.), Identidade e diferença: A perspectiva dos estudos culturais (8a ed., pp 103-113). Petrópolis, RJ: Vozes.

Hooks, B. (2005). Alisando nosso cabelo (L. M. Santos, trad.). Revista Gazeta de Cuba - Unión de escritores y artista de Cuba. Recuperado de https://www.geledes.org.br/alisando-o-nossocabelo-por-bell-hooks/

King, A. M. (2015, Março 28). Os cabelos como fruto do que brota de nossas cabeças. Geledés Instituto da Mulher Negra. Recuperado de https://www.geledes.org.br/os-cabelos-como-fruto-do-quebrota-de-nossas-cabecas/\#axzz3ZBeYdmWy

Louro, G. L. (2001). Compondo identidades. In G. L. Louro (Org.), O corpo Educado: Pedagogias da sexualidade (2a ed., pp. 14-16). Belo Horizonte: Autêntica.

Malta, R. B., \& Oliveira, L. T. B. (2016). Enegrecendo as redes: O ativismo de mulheres negras no espaço virtual. Gênero, 16(2), 55-69. Recuperado de http://www.revistagenero.uff.br/index.php/revistagenero/articl e/view/811/436

Matos, E. M. S. (2015). Cachear e Encrespar: Moda ou resistência? Um estudo sobre a construção identitária do cabelo afrodescendente em blogs (Monografia de Bacharelado). Universidade de Brasília, Brasília, DF, Brasil. Recuperado de http://bdm.unb.br/bitstream/10483/12124/1/2015_EdilaMariad osSantosMatos.pdf

Mattos, I, G., \& Silva, A. (2014). Vício cacheado: Estéticas afro diaspóricas. Revista Da Associação Brasileira De Pesquisadores/as Negros/as (ABPN), 6(14), 214-235. Recuperado de http://www.abpnrevista.org.br/revista/index.php/revistaabpn1/ article/view/139/137

Oliveira, A. P. O. (2017). "Que experiências seu cabelo te traz?" (Monografia de Bacharelado). Universidade do Estado do Rio de Janeiro, Rio de Janeiro, RJ, Brasil.

Schucman, L. V. (2018). "O racismo familiar e a construção da negritude positivada: da química ao crespo". In L. V. Schucman, Famílias inter-raciais: Tensões entre cor e amor. Salvador: EDUFBA.

Schucman, L. V. (2010). Racismo e antirracismo: A categoria raça em questão. Revista Psicologia Política, 10(19), 41-55. Recuperado de

http://pepsic.bvsalud.org/scielo.php?script=sci_arttext\&pid=S1 519-549X2010000100005 


\section{Endereço para correspondência}

Aryanne Pereira de Oliveira e Oliveira

Rua Angélica Mota, 150, apt 105, Olaria, CEP 21021-490, Rio de Janeiro - RJ, Brasil Endereço eletrônico: aryannepoo@gmail.com

\section{Amana Rocha Mattos}

Universidade do Estado do Rio de Janeiro

Rua São Francisco Xavier, 524, sala 10.019, bloco F, Maracanã, CEP 20550-900, Rio de Janeiro - RJ, Brasil

Endereço eletrônico: amanamattos@gmail.com

Recebido em: 03/04/2019

Reformulado em: 29/06/2019

Aceito em: 02/07/2019

\section{Notas}

* Graduada em Psicologia pela Universidade do Estado do Rio de Janeiro. Atualmente, cursa o Programa de Residência Multiprofissional em Saúde da Mulher pela Universidade Federal do Rio de Janeiro.

** Mestre e Doutora em Psicologia pela Universidade Federal do Rio de Janeiro. É Professora Adjunta do Instituto de Psicologia e Professora Permanente do Programa de Pós-Graduação em Psicologia Social da Universidade do Estado do Rio de Janeiro.

${ }^{1}$ Este artigo é fruto do trabalho de conclusão do curso de graduação em Psicologia de autoria da primeira autora, intitulado "Que experiências seu cabelo te traz?" (Oliveira, 2017), e orientado pela segunda autora. Gostaríamos de agradecer às professoras Alexandra Cleopatre Tsallis (IP/UERJ) e Conceição Firmina Seixas Silva (FE/UERJ), que integraram a banca de avaliação da monografia, por suas valiosas contribuições, que estimularam a produção deste artigo.

${ }^{2}$ A esse respeito, consultar Emília Viotti da Costa. Segundo a autora, "[...] o mito da Democracia Racial era uma distorção do padrão das relações raciais no Brasil, construído ideologicamente por uma elite considerada branca, intencional ou involuntariamente, para maquiar a opressiva realidade de desigualdades entre negros e brancos." (Costa, 1979, p. 231)

3 Os textos consultados podem ser acessados através dos seguintes links, respectivamente: Blogueiras Negras: http://blogueirasnegras.org/2015/02/02/relato-de-uma-transicao-comoempoderamento-e-reconhecimento/; Projeto http://projetoredomas.com/fala-sobre-o-teu-cabelo-nega/;

Redomas: https://www.geledes.org.br/menina-negra-e-escola/; https://www.geledes.org.br/mulher-negra-o-outro-do-outro/; Geledés: Geledés: https://www.terra.com.br/vida-e-estilo/beleza/cabelos/cabelos-crespos-mulheresfalam-sobre-direito-ao-corpo-e-penteadoafro,8c5198a24a2d1a2177869d23f62c385b0gwrRCRD.html

Este artigo de revista Estudos e Pesquisas em Psicologia é licenciado sob uma Licença Creative Commons Atribuição-Não Comercial 3.0 Não Adaptada. 